\title{
Traduções no teatro, feitas para publicar, encenar ou legendar: uma tipologia possivel
}

\author{
Theatre translation, made for page, for \\ stage or for subtitling: a possible typology
}

Ruth Bohunovsky ${ }^{1}$ 


\section{Resumo}

Partindo das premissas teóricas da tradução funcionalista - que tem o escopo do trabalho como seu conceito central - procura-se diferenciar diversos tipos de tradução no meio teatral. A discussão limita-se à tradução interlingual de textos escritos. $\mathrm{O}$ artigo propõe a distinção entre três tipos básicos de tradução teatral: a tradução literária, a tradução performável ${ }^{2}$ e a tradução para legenda. Em oposição a abordagens tradicionais, que privilegiam um determinado tipo de tradução em detrimento de outro, defende-se que os três tipos cumprem funções importantes nos sistemas literário e teatral de um determinado contexto linguístico e cultural, requerendo, no entanto, escopos e, portanto, estratégias de tradução diferenciados.

Palavras-chave: Tradução funcionalista; tradução teatral; tradução literária; tradução performável; legendagem

\section{Abstract}

Starting from the theoretical premises of functional translation - which has the skopos of translation as central concept - this article proposes to differentiate between some types of theatre translation. The discussion is limited to interlingual translation of written texts. It proposes to distinguish between three basic types of theatrical translation: literary translation (for page), translation for performance (for stage) and translation for subtitling. In contrast to traditional approaches, which privilege one type of translation over another, it is argued that the three types fulfil important functions in the literary and theatrical systems of a particular linguistic and cultural context, yet require different scopes and, therefore, translation strategies.

Keywords: Functional translation; theatre translation; literary translation; performatic translation; subtitling

\footnotetext{
1 Profa. Dra. na Universidade Federal do Paraná (UFPR), área de alemão (pesquisas em Alemão como Língua Estrangeira, Tradução, Literatura austríaca) - ruth. bohunovsky@gmail.com. O presente artigo foi elaborado no âmbito do projeto de pesquisa "Traduzir o teatro e o cômico: formas e funções do cômico em textos teatrais contemporâneos da Áustria", contemplado com uma bolsa de pesquisa Franz Werfel do ÖAD (Serviço de Intercâmbio Austríaco) para a realização de um pós-doutorado nas universidades de Viena e Graz (março de 2019 até fevereiro de 2020).

2 "Tradução performável" é uma tentativa de traduzir para o português a expressão "bühnenwirksame Übersetzung" (Hörmanseder). Optamos por essa tradução para diferenciar a definição da "tradução teatral" mais abrangente, evitando, ao mesmo tempo, a opção mais ambígua de "tradução performativa", que não nos parece adequado, pois haveria a possibilidade de esta expressão ser confundida com o próprio processo do trabalho tradutório. A ideia é que o termo se refira a uma tradução que resulte num texto que possa ser encenado num palco, ou seja, uma tradução adequada para o palco. Entendemos que a expressão tradução performável cumpre essa finalidade.
} 


\section{Introdução}

O teatro é um espaço de múltiplas traduções. O diretor de um espetáculo pensa em como "traduzir" melhor um drama clássico do século XIX sobre uma figura heroica e/ou histórica para o público do século XXI, que já nem conhece mais o contexto histórico espelhado no enredo da peça. Após uma apresentação recente da peça "Sorte e fim do rei Ottokar" num dos maiores teatros de Viena3, durante uma conversa dos atores com o público, o assunto foi justamente este: como montar de forma interessante e significativa para o público europeu da atualidade uma peça escrita em 1823 sobre um rei da Boêmia do século XIII? Sem uma "tradução" adequada, a peça dificilmente encontraria um teatro disposto a incluí-la na programação e não teria o sucesso que está tendo atualmente na capital austríaca. Nesse caso, trata-se de uma "tradução intralingual", que implica a reformulação de signos verbais na mesma língua (Jakobson, 2000). Mas há outros tipos: os atores e atrizes de uma peça também se entendem como "tradutores" de seus personagens ao quais precisam dar vida e personalidade, às vezes com grandes alterações de uma montagem para outra (a "tradução intersemiótica", que envolve a interpretação de signos verbais por signos não verbais (Jakobson, 2000)). Pensemos, por exemplo, nas diversas e contraditórias "traduções" dadas ao judeu Shylock do "Mercador de Veneza" de Shakespeare ao longo da história. Nas palavras da teórica de tradução teatral Sirkku Aaltonen, não há apenas "um Esperando Godot", mas há "tantos Godots como há encenações" e cada produção pode reivindicar "autenticidade e legitimidade"4 $(2000$, p. 1) para seu projeto cênico, que pode incluir cortes, acréscimos, alterações de passagens textuais, alusões a contextos extralinguísticos atuais etc. em relação ao texto originalmente escrito ou publicado. É um "processo contínuo de interpretação e redirecionamento dos códigos redigidos no texto teatral original" que resulta na "efemeridade de uma produção cênica" (Aaltonen, 2000, p. 3).

Toda encenação de um texto teatral - assim como toda comunicação humana - é um ato de tradução (Steiner, 2005) e envolve interpretação, manipulação e transformação. Assim como faz todo tradutor em seu trabalho, nos exemplos acima mencionados, cada diretor/a e cada ator/atriz inevitavelmente deixará seu cunho idiossincrático na interpretação, dependendo tanto de sua subjetividade quanto de fatores contextuais.

A tradução no teatro movimenta-se entre a oralidade e a escrita, é heterogênea e complexa. Não existe "a" tradução no teatro, existem inúmeras formas de se pensar sobre tradução teatral ${ }^{5}$, mesmo considerando "apenas" os casos que envolvem duas línguas, que serão nosso foco aqui. Pode-se fazer uma tradução de uma peça a partir do interesse de uma companhia de teatro em encená-la (levando em consideração

\footnotetext{
3 No Volkstheater de Viena, em 20 de março de 2019; a peça Sorte e fim do rei Ottokar [König Ottokars Glück und Ende] é uma obra do dramaturgo austríaco Franz Grillparzer (1791-1872).

4 Todas as traduções citadas neste artigo, salvo indicação explícita de outro nome, são nossas.

5 No presente artigo, usamos o termo "tradução teatral" como um conceito amplo que inclui tanto a tradução de textos escritos na forma dramática e cujo objetivo é ser encenado, mas também a tradução de textos dramáticos apenas para a leitura (dramática ou não), a tradução/adaptação de textos em prosa para serem encenados etc. - ou seja, a tradução de qualquer texto para outra língua que, de um modo ou de outro, possa ser relacionado com o teatro.
} 
os interesses, as possibilidades e limitações desse grupo), para ser lançada em forma de livro (havendo ou não o propósito de uma montagem imediata) ou para acompanhar uma apresentação de um espetáculo em língua estrangeira em forma de legenda. Podemos pensar também numa tradução feita para ser passada ao público via fone de ouvido simultaneamente durante um espetáculo. Nesse caso, os produtores e tradutores precisam encontrar soluções para o fato de que o ritmo varia entre uma apresentação e outra, o que impede que a tradução simultânea seja transmitida por um computador de modo automático. Cada vez mais há também traduções de peças teatrais para a língua de sinais, possibilitando a inclusão de um público até agora pouco presente nas plateias dos teatros. Ou seja, podemos identificar diferentes tipos de tradução teatral que, embora sem limites fixos e claros, têm objetivos divergentes e, portanto, requerem estratégias tradutológicas diferenciadas.

As reflexões apresentadas neste artigo concentram-se em casos em que acontece uma passagem, uma transformação, de um texto teatral escrito em uma determinada língua para um texto teatral escrito em outra língua - ou seja, em casos de "tradução interlingual" (Jakobson, 2000). Procuramos apresentar uma tipologia básica para a tradução interlingual no contexto teatral e algumas reflexões sobre as diferentes estratégias que esses tipos de trabalho requerem. Nosso objetivo não é estabelecer classificações fixas ou propagar estratégias normativas, mas frisar a importância de se levar em consideração nesse caso, assim como em qualquer projeto tradutório, o contexto e o objetivo específico, o escopo da respectiva tradução. Nesse intuito, partimos das discussões teóricas desenvolvidas no âmbito da vertente funcionalista de tradução (p. ex. Nord, 2011), visando especificamente o contexto teatral (p. ex. Aaltonen, 1995, 2000; Hörmanseder, 2008; Snell-Hornby, 1984). O conceito central para nossas reflexões e para se realizar e avaliar uma tradução é o de escopo (o objetivo ou a finalidade que se estabelece para uma tradução), o qual dá destaque ao contexto em que se insere o texto traduzido, e não àquele em que foi escrito o texto de partida.

Mais que apresentar um aprofundamento em pormenores teóricos e/ou conceituais da tradução funcionalista e/ou teatral, procuramos ilustrar nossa proposta tipológica com exemplos e com vozes que provêm da prática teatral e tradutológica - e que às vezes evidenciam visões e opiniões bastante diversas e até opostas - , tanto do Brasil quanto de outros países.

Em relação à teoria, merece ser lembrado que ela tem passado por uma fase de crescimento de prestígio e valorização, pelo menos há alguns anos. Em 1998, Susan Bassnett lamentou que a área dos estudos de tradução teatral ainda fosse "o campo mais problemático e negligenciado dos estudos da tradução" (Bassnett, 1998, p. 90). Desde então, e sobretudo na última década, a tradução teatral tem sido objeto de diversos estudos, tanto assim que Serón-Ordóñez chega a intitular sua apresentação detalhada e comentada sobre a produção bibliográfica escrita mais recentemente acerca do tema "Os estudos de tradução teatral: um panorama sobre um campo em crescimento (Segunda parte: do começo do século XXI até 2014)" (2014) [Theatre translation studies: An overview of a burgeoning field (Part II: From the early 2000s to 2014]. Na medida do necessário para corroborar nossa argumentação, algumas 
dessas referências teóricas serão citadas a seguir, sem que pretendamos, porém, apresentar uma análise pormenorizada da grande heterogeneidade de abordagens e visões nesse âmbito ${ }^{6}$.

\section{Por uma adequação funcional da tradução teatral}

Ao se partir de uma visão funcionalista da tradução, entende-se que nenhum texto possui um significado implícito, intrínseco, que possa ser compreendido "corretamente" ou levado de modo "fiel" para outra língua. A teoria funcionalista, também conhecida como teoria do escopo (objetivo, finalidade), da qual Christiane Nord é uma das exponentes mais conhecidas ${ }^{7}$, parte da premissa de que qualquer texto é uma ação que visa cumprir uma determinada função. O que está em primeiro plano ao se realizar ou avaliar uma tradução é, portanto, a sua finalidade. O mesmo texto pode ser traduzido tendo em vista diferentes finalidades (escopos), o que resulta, consequentemente, em textos de chegada bastante diversos. Em substituição à ideia de uma suposta "fidelidade" - que pressupõe algo estável que posso levar "fielmente" para outra língua e que tem sido amplamente questionada ao longo das últimas décadas (p. ex. Arrojo, 1986), mas que ainda serve de argumento em muitas discussões sobre o tema -, Nord tem proposto os termos de "adequação ao escopo" e "lealdade". Subentende-se que uma tradução pode e deve ser "adequada" para o contexto dentro do qual se propõe a funcionar e que o tradutor deveria procurar ser leal tanto ao autor que traduz (e àquilo que sabe sobre suas ideias, seus propósitos etc.), como também ao contratante, aos objetivos específicos e ao destinatário de seu trabalho (Nord, 2011). Para nossa discussão, é ainda relevante a diferenciação que Nord estabelece entre dois tipos básicos (cada um com diversos subtipos ${ }^{8}$ ) da prática tradutória: a "tradução documento" e a "tradução ferramenta". A primeira referindo-se a traduções feitas com o escopo de permitir ao destinatário uma aproximação com "determinados aspectos de uma ação comunicativa do passado", a segunda tendo como meta primordial o funcionamento do "objetivo comunicativo" da própria tradução (Nord, 2011, p. 22-25).

A vertente funcionalista não se embasa numa intenção politicamente tão marcada como, por exemplo, a de Lawrence Venuti e a sua defesa da "visibilidade" do tradutor (Venuti, 2018), mas abre caminhos para um leque grande de projetos tradutológicos com escopos diversos, entre os quais a tradução "estrangeirizante" nos termos de Venuti, que seria uma das possibilidades do tradutor ${ }^{9}$. No contexto da vertente funcionalista, a diferenciação entre a "boa" e a "má" tradução a partir de critérios linguísticos e intrínsecos aos textos de partida e de chegada foi substituída

\footnotetext{
6 Para um panorama informativo e abrangente da produção bibliográfica especializada sobre a tradução teatral, cf. as duas partes do estudo de SERÓN: Theatre translation studies: An overview of a burgeoning field (Part I: Up to the early 2000s) e Theatre translation studies: An overview of a burgeoning field (Part II: From the early 2000s to 2014), ambas publicadas na revista Status Quaestionis (2013 e 2014).

7 Outros teóricos representativos dessa vertente são, por exemplo, Hans Vermeer e Katharina Reiss.

8 Cf. Nord (2011).

9 Um projeto que procura discutir e aplicar as ideias de Venuti no âmbito da tradução e da prática teatral é Translating Theatre, da Universidade de Kent (cf.: $<$ http://www.translatingtheatre.com/the-project/>).
} 
por uma discussão acerca da "adequação funcional" de um determinado produto tradutório. Além disso, a diferenciação entre "tradução" e "adaptação" (um termo frequente quando se trata de peças de teatro) também se tornou flexível, pois, para ser "funcionalmente adequado", um texto teatral pode eventualmente sofrer grandes interferências formais ao ser transposto de uma língua para outra, sem deixar de ser prontamente considerado uma tradução. Um exemplo seria o caso famoso das versões francesas dos dramas shakespearianos, as afamadas "belas infiéis", do século XVIII, em que os tradutores costumavam mudar os enredos das peças, o número dos personagens previstos e a forma métrica, eliminavam resquícios de comicidade e de vulgaridade e, ao contrário do que acontece na peça original, seguiam à risca a unidade de tempo, lugar e ação - sem que os produtos resultantes de tais estratégias tivessem deixado de ser chamados de "traduções" (cf., por exemplo, Aaltonen, 2000, p.84). Já em outros contextos, versões bem mais próximas ao original foram chamadas de "adaptação", por motivos diversos, inclusive questões ligadas ao pagamento de direitos autorais. Ou seja, a diferenciação entre "tradução" e "adaptação" - esta algo tão frequente no caso de textos teatrais - depende muito mais de fatores extratextuais do que de questões linguísticas intrínsecas ao original e sua transposição para outra língua.

Uma teórica que tem se dedicado exclusivamente ao tema da tradução no contexto teatral é a finlandesa Sirkku Aaltonen. Seu livro Time-Sharing on Stage: Drama Translation in Theatre and Society (2000) traz argumentos e exemplos que corroboram a discussão aqui desenvolvida. A autora cita, por exemplo, a necessidade de se levar em conta se um texto dramático e/ou teatral é previsto para circular e "funcionar" dentro do sistema literário ou do sistema teatral ${ }^{10}$, pois "nem todo drama que é traduzido é também encenado ou destinado para uma produção no palco, alguns dramas podem existir apenas dentro do sistema literário, como texto publicado" (Aaltonen, 2000, p. 4). A teórica ainda complementa que "textos dramáticos escritos podem funcionar fora do sistema teatral e, vice-versa, o sistema teatral pode funcionar sem eles" (Aaltonen, 2000, p. 34). A distinção entre sistema literário e sistema teatral é relevante na tipologia que propomos a seguir, pois ilustra que um texto dramático e/ou teatral pode ser traduzido para fazer parte de apenas um desses dois sistemas gerais (embora eles nunca sejam independentes um do outro), o que justificaria a aplicação de estratégias diferentes no processo de tradução.

Aaltonen ilustra bem sua visão sobre a tradução teatral quando afirma que o título de seu próprio livro Time-Sharing on Stage ela tomou emprestado da obra Practices of Everyday Life, do filósofo francês Michel de Certeau (1984), "que compara textos com apartamentos alugados", onde os inquilinos podem realizar alterações consideráveis nos diversos cômodos (Aaltonen, 2000, p. 9). "Assim como os inquilinos, tradutores e leitores redecoram os textos" quando se aproximam deles (Aaltonen, 2000, p. 9). Dependendo sempre daquilo que os tradutores - ou seja, os "inquilinos" - definem como sua função e finalidade (na terminologia da tradução funcionalista, seu escopo), tais "redecorações" podem ganhar as formas mais diver-

10 Para uma discussão mais aprofundada sobre as teorias sistêmicas nas quais se baseia Aaltonen para sua argumentação, veja, por exemplo, In Search of a Theory of Translation (Toury, 1980) ou Polysystem studies (Even-Zohar, 1990). 
sas: ou tratam o ambiente com "reverência", quando o "texto estrangeiro não parece precisar de nenhum ajuste, ou apenas de muito pouco", ou alteram o ambiente com espírito "rebelde", permitindo-se mudanças de porte maior. Tais posturas dependem de fatores extratextuais, que podem ser ideológicos, estéticos, legais etc. Partindo da argumentação de Aaltonen examinaremos a seguir a questão das adaptações textuais realizadas no contexto teatral, as quais, dependendo do seu respectivo contexto mediático, são consideradas possíveis, permitidas, convencionais e/ou previsiveis. Observamos que em alguns momentos a autora menciona esse ponto, porém não se detém em maiores análises. Os exemplos aqui apresentados provêm primordialmente do par linguístico português - alemão, nosso campo de trabalho e de pesquisa.

\section{A tradução literária de textos dramáticos}

O primeiro tipo de tradução no teatro é aquele que não é destinado a chegar aos palcos, ou seja, é a tradução de um texto dramático feita com o intuito de ser publicada e lida como parte do sistema literário de uma nova língua, e não como base para uma encenação dramática. Uma tradução desse tipo pode ter como texto de partida um closet drama (isto é, um texto dramático originalmente escrito apenas para ser lido), embora qualquer texto dramático possa ser traduzido com esse objetivo.

A característica mais marcante de traduções literárias de textos dramáticos é que elas não precisam levar em consideração fatores relacionados a uma eventual performance frente a um público (como é o caso nos outros tipos, discutidos mais adiante). Seguindo a terminologia de Christiane Nord, trata-se geralmente de traduções "documento", ou seja, pensadas para oferecer ao leitor um acesso a uma determinada "situação comunicativa do passado" e, eventualmente, também a seu contexto original, e não necessariamente para "funcionar" como texto dramático na língua-alvo. Como aponta Aaltonen, traduções desse tipo procuram "escrever o texto de partida com as palavras da língua-alvo" (2000, p. 32), ainda que, obviamente, "sempre reescrev[am] o texto de partida" e "nunca po[ssam] ser uma réplica exata" deste (2000, p.72).

Traduções deste primeiro tipo tendem a ser chamadas de mais "fieis", pois em um cotejo com o original mostrarão grande proximidade com as características linguísticas, a extensão do texto e o número de personagens previstos no texto de partida. Porém, do ponto de vista de profissionais do teatro, elas ganham frequentemente adjetivos como "eruditas" ou "acadêmicas" e avaliações negativas. Snell-Hornby relata, por exemplo, a existência de uma "desavença" entre os filólogos e práticos de teatro no que tange à forma ideal de uma tradução teatral (Snell-Hornby, 1984, p. 102). Traduções literárias seriam, para muitos diretores, dramaturgistas ${ }^{11}$ e atores,

\footnotetext{
11 Bastante presente nos teatros de língua alemã, o termo "dramaturgista" e sua função profissional são pouco conhecidos no Brasil. Segunda Fátima Saadi que prefere o termo "dramaturgista" ao de "dramaturg", apesar de ele ainda não estar dicionarizado, para marcar melhor a diferença em relação ao "dramaturgo" (Saadi, 2013, s.p.) -, no nosso país "a prática do dramaturgista se inicia nos anos de 1970" quando, geralmente, estava associada a "espetáculos de jovens diretores que buscavam caminhos estéticos singulares, distintos tanto do teatro militante quanto do teatro comercial" (Saadi, 2013, s.p.). Ao falar do dramaturgista, referimo-nos à pessoa responsável, entre outras funções, por "intervir diretamente na produção dos vários espetáculos provendo suporte crítico ao encenador para a interpretação de cada texto" <http://www.spescoladeteatro.org.br/coluna/dramaturgo-dramaturg-dramaturgista/>. Entendemos que, no contexto brasileiro, é muitas vezes o próprio tradutor que assume essa função - a imagem do tradutor como dramaturgista é usada também por Pavis (1989, p. 27) (cf. também Phyllis Zatlin. Theatrical translation and film adaption: A practitioner's view. Clevedon: Mulitlingual Matters, 2005). Para mais informações sobre a história e o papel do/da
} 
resultado do trabalho de "acadêmicos entusiastas" e "mais um obstáculo do que uma ajuda" na passagem do texto dramático para o palco (Laskowski, 1996, p. 193 apud Aaltonen, 2000, p. 40), por serem "desastrosas, sem vida, sem cor, como um tapete turco visto pela parte de trás" (Johnston, 1996, p. 10 apud Aaltonen, 2000, p. 40). A visão crítica sobre esse tipo de tradução por parte de profissionais do teatro tem uma longa tradição; já no século XIX, o alemão Ludwig Tieck se referia às "expressões meio desajeitadas" e "muito usadas pelo estudioso, o filólogo que não é capaz de entender a fala real, o diálogo natural e verdadeiro do teatro" (Tieck apud Snell-Hornby, 1984, p. 102). Tais avaliações negativas não são, porém, necessariamente resultado de uma tradução malfeita, mas de uma avaliação feita por alguém que tem em mente uma tradução com um escopo diferente. Para fazer parte do sistema literário, tais traduções destinadas a leitores e estudiosos podem ser não apenas de grande ajuda, mas também de alta qualidade e nível filológico. Além disso, como aponta Serón-Ordóñez, referindo-se a estudos de Zatlin (2005, cf. nota 11) e Minier ${ }^{12}$, traduções "literais" - isto é, aquelas que procuram manter uma estreita relação semântica e sintática com o texto de origem - são fundamentais em produções cênicas no Gate Theatre, por exemplo, pois só com tais versões literárias e após comunicação com o tradutor "literal" o teatro reconhece os direitos autorais da produção (Serón-Ordóñez, 2014, p. 54). Aliás, após uma análise rigorosa da literatura especializada sobre o tema da tradução teatral, produzida entre 2000 e 2014, Serón-Ordóñez chega à conclusão de que, atualmente, não se pode mais concordar com a avaliação muito difundida de que a tradução "para a página" [translation for the page] tenha sido substituída pela tradução "para o palco" [translation for the stage]. De acordo com a estudiosa, "o oposto que é verdade" (Serón-Ordóñez, 2014, p. 55), pois "na literatura recente" pode-se observar uma "reorientação" em direção ao texto de partida, "em oposição ao foco anterior acerca da cultura-alvo e ideias próximas de egoísmo tradutório, apropriação etc." (Serón-Ordóñez, 2014, p. 60).

Referindo-nos ao modelo teórico de Aaltonen, as traduções literárias são aquelas versões que "seguem as convenções do sistema literário, independentemente de sua proximidade ou distância das convenções da tradução performável" (2000, p. 44). E por seguirem as convenções válidas para traduções dentro do sistema literário (Aaltonen, 2000), elas estão sujeitas à crítica nesse âmbito e às implicações legais em torno dos direitos autorais. Resultam, geralmente, em versões do texto de partida integral, sem cortes e/ou acréscimos de novas passagens, sem alusões ao contexto sociopolítico da língua de chegada e são lançadas, frequentemente, em publicações bilíngues.

Um exemplo desse tipo no contexto brasileiro é a tradução de "Os últimos dias da humanidade" [Die letzten Tage der Menschheit], uma obra do satirista austríaco Karl Kraus. Escrita entre 1915 e 1922 em reação à Primeira Guerra Mundial, a obra compõe-se de 220 cenas, muitas delas sem relação com as outras, e foi denominada

dramaturgista no Brasil sugerimos a leitura de Saadi (2013) e do artigo "O Laboratório do Dramaturg e os Estudos de Genética Teatral: experimentos" (2011), de Maria de Lourdes Rabetti, http://www.scielo.br/pdf/rbep/v1n2/2237-2660-rbep-1-02-00443.pdf.

12 Márta Minier. "To only use texts where absolutely necessary": An interview with Natalie Abrahami about diretor-led adaptations of classics, her work at the Gate Theatre and Yerma. Journal of Adaptation in Film\&Performance, 5, 2, p. 197-213, 2012. 
pelo próprio autor como "teatro para ser encenado em Marte", devido à aparente impossibilidade de se poder levá-la ao palco na Terra. Ou seja, uma obra concebida pelo autor como closet drama - mas que já teve passagens encenadas em diversos projetos performáticos nos países de língua alemã, o mais recente em Wiener Neustadt, perto de Viena, uma performance de mais de sete horas que cortou dois terços do texto original ${ }^{13}$. Em 1929, próprio Kraus e o diretor Max Reinhart realizaram uma adaptação desse texto para o palco na qual reduziram as originais 800 páginas a 250 . Em 2017, saiu, pela editora Balão Editorial, a primeira tradução brasileira dessa versão já reduzida, realizada por Mariana Ribeiro de Souza. Independentemente de essa obra megalomaníaca encontrar ou não (o que é mais provável) seu caminho para um projeto de encenação em solo brasileiro, ela não foi traduzida com esse intuito, e sim para possibilitar ao público o contato com uma obra literária canônica e de relevância internacional. Numa entrevista concedida a Paulo Vitor Schlichting Peçanhuk e publicada na revista Qorpus, da Universidade Federal de Santa Catarina, a tradutora não se refere em nenhum momento à possibilidade de uma montagem brasileira da peça, mas ressalta a importância de sua divulgação: "creio que uma obra cujo título possui a palavra humanidade não pode ficar circunscrita ao mundo de língua alemã. Ela deve e tem que transcender estas fronteiras para iluminar a todos nós" (Souza, 2018, s.p.). Os paratextos que acompanham a tradução brasileira também não tratam, em momento algum, do potencial performático da peça, mas abordam questões relacionadas à importância literária de Kraus, ao uso que ele faz da língua, ao grande potencial crítico no contexto original e outras idiossincrasias do autor e da peça ${ }^{14}$.

Conforme já mencionado acima, muitos teóricos e profissionais do teatro - por exemplo, Fabienne Hörmanseder, defensora da ideia de que a tradução no contexto teatral deve ser "adequada para o palco" (2008) - rejeitam a tradução literária de textos dramáticos, pois entendem que isto supõe "presumir que a totalidade dos signos do texto literário sejam idênticos à totalidade dos signos no teatro" (Hörmanseder, 2008 , p. 20). A nosso ver, nos casos em que textos dramáticos fazem parte do sistema literário (inclusive em línguas diferentes daquela em que foram escritos originalmente), tal compreensão negativa não deve ser aplicada. Traduções feitas com um escopo literário, filológico, não deixam de ser textos dramáticos, mas se encontram num lugar de interface entre o sistema literário e o sistema teatral. Traduções destinadas a esse fim devem ser realizadas e avaliadas levando-se em consideração as especificidades do sistema literário - e não rejeitadas por (talvez) serem inadequadas em relação a um suposto escopo único, a encenação em cima de um palco.

\section{A tradução performável}

Aaltonen resume a diferença entre a tradução literária e a tradução performável ${ }^{15}$ de textos teatrais da seguinte maneira: o segundo tipo

\footnotetext{
13 Cf.: <www.letztetage.com>.

14 Cf. a "Introdução" e o "Pósfácio" na versão brasileira: Barbosa (2017) e Bohunovsky (2017)

15 Aaltonen denomina de "theatre translation" aquilo que, no presente artigo, denominamos de "tradução performável", pois usamos o termo "tradução teatral" num sentido mais geral, para nos referirmos a qualquer tradução (escrita ou oral) que tenha relação com o teatro. Assim, a "tradução teatral" é, neste artigo, um
} 
tradicionalmente estabelece com seu texto de partida uma relação diferente que uma tradução feita para o sistema literário, em que a tradução não envolve uma mudança de mídia. No sistema literário, a mídia continua a mesma, ou seja, um texto escrito é traduzido e publicado como um texto escrito, enquanto no teatro o texto se torna um elemento de uma performance no palco. No teatro, a oralidade, o imediato e a comunidade inevitavelmente introduzem uma nova dimensão à tradução de textos. Enquanto na tradução literária, o discurso anglo-americano enfatiza a invisibilidade do tradutor e a fidelidade da tradução (Venuti, 1995a, p. 1), a tradução performável produz ativamente reescrituras ou adapta muitos aspectos do texto-fonte, justificando essa estratégia com base nas "exigências do palco" e em critérios como "performabilidade" e "pronunciabilidade". (Aaltonen, 2000 , p. 41). ${ }^{16}$

Se a tradução literária de um texto dramático implica um interesse do tradutor (e do destinatário) pelo texto e pelo contexto do original, no caso da tradução performável nos aproximamos daquilo que é chamado tradicionalmente de "exigências do palco". De um modo geral, podemos definir o escopo desse tipo de tradução como sendo a disponibilização de textos teatrais e a viabilização de futuras encenações em um novo contexto linguístico. Embora a tradução desse tipo possa também ser destinada à publicação e, portanto, sua leitura possa anteceder ou substituir a encenação, ela procurará levar em conta fatores relacionados ao contexto cênico e performático de uma eventual montagem. De acordo com Aaltonen, a tradução performável resulta, pelo menos em alguns casos, também numa postura autoral mais visível e perceptível do tradutor, o que implica inclusive pagamentos maiores para quem faz esse tipo de tradução, muitas vezes chamado de "adaptação" - pelo menos é o que parece acontecer na prática dos contratos da BBC, de acordo com Aaltonen (2000, p. 45).

Outra característica desse tipo de texto é que, muitas vezes, o tradutor é visto como um dos membros responsáveis pela produção artística como um todo. Essa ideia já tinha sido apadrinhada por Snell-Hornby, nos anos 1980. Alguns teóricos têm assumido uma postura bastante prescritiva em sua defesa (cf. Serón-Ordóñez, 2014, p. 34). No entanto, nos distanciamos dessa posição entendendo que nenhum tipo de tradução deve ser favorecido antes de que seus objetivos, seu contexto concreto e as reais possibilidades de o texto em questão ser traduzido sejam conhecidos. Porém, se o escopo da tradução é produzir a base textual para uma encenação adequada do ponto de vista dramatúrgico, a colaboração entre tradutor, diretor, atores (e, eventualmente, também o público ${ }^{17}$ ) parece mais que desejável. Assim, conforme observado também por Bigliazzi, Kofler e Ambrosi (2013), a abordagem holística nos moldes de Snell-Hornby ainda encontra forte ressonância em estudos atuais em que o tradu-

\footnotetext{
conceito que abrange diversos tipos de tradução (literária, performável, legendagem). Por isso, traduzimos aqui o conceito de "theatre translation" de Aaltonen por "tradução prefomável".

16 No original: [...] traditionally relates to the source text differently from its counterpart in the literary system where translation does not involve a change of medium. In the literary system, the medium remains the same, that is, a written text is translated and published as a written text, whereas in the theatre, orality, immediacy and communality unavoidably introduce a new dimension to the translation of texts, and, while in literary translation contemporary Anglo-American discourse emphasises the translator's invisibility and the faithfulness of the translation (Venuti, 1995a: 1), theatre translation actively rewrites, or adapts, many aspects of the source text, justifying this strategy with references to the 'requirements of the stage' and criteria such as 'playability' and speakability'. $O$ livro de Venuti ao qual Aaltonen se refere nessa passagem é: Venuti, Lawrence. The Translator's Invisibility. A history of Translation. Londres e Nova York: Routledge, 1995.

17 Cf. Roger Baines; Fred Dalmasso. A text on trial: The translation and adaptation of Adel Hakim's Exéctuer 14. Social Semiotics, 17, 2, p. 229-257, 2007. Nesse trabalho, os autores refletem sobre a relação mútua entre as suas decisões tradutórias e a recepção da montagem pelo público.
} 
tor é considerado "co-sujeito e/ou co-autor da performance, competente tanto em questões textuais, cênicas e performativas, em estilo verbal e gestual, quanto no que tange a convenções da atuação: uma figura indispensável da mediação cultural e teatral" (Bigliazzi; Kofler; Ambrosi, 2013 apud Serón-Ordóñez, 2014, p. 58). ${ }^{18}$

Diversos teóricos têm se debruçado sobre esse tipo de tradução e destacado conceitos como pronunciabilidade [speakability] e performabilidade [performability] como centrais para traduções que tenham como escopo a produção de textos dramáticos aceitáveis e adequados dentro do sistema teatral. Diferentes maneiras de entender e definir tais conceitos têm sido apresentadas. Por exemplo: Levy (1969), Bassnett (1990) e Serón-Ordóñez (1984), com suas discussões, ilustram a dificuldade (impossibilidade?) de se chegar a definições claras, definitivas e objetivas. Num artigo de 2010, Fernandes propôs uma definição que, embora (ou justamente por esta razão) bastante geral, nos parece adequada para ilustrar aqui os referidos conceitos. Segundo a teórica, a "performabilidade vai além da pronunciabilidade" (Fernandes, 2010, p. 131) - que enfoca a adequação para a pronunciação do ator e da atriz -, pois leva em conta também a audiência. Portanto, produzir uma versão levando em consideração a performabilidade significa "traduzir um texto teatral no intuito de torná-lo pronunciável para os atores e dar forma à linguagem de um tal modo que atraia o público para o aqui e agora da performance" (Fernandes, 2010, p. 130-131).

Em sua tese de doutoramento também baseada numa abordagem funcionalista e que foi orientada pela teórica de tradução Mary Snell-Hornby, Fabienne Hörmanseder defende e tenta definir o que entende por uma tradução "adequada para o palco" [bühnenwirksame Übersetzung]. Embora não concordemos com essa teórica quando ela afirma, em seu estudo depois publicado em livro, que "um texto dramático só é traduzido quando é destinado para uma encenação" (Hörmanseder, 2008, p. 66; destaque nosso), suas explanações são bastante úteis ao se pensar sobre a tradução performável. Segundo Hörmanseder, o texto dramático "não foi escrito para ser lido, mas para ser ouvido, criado para um público, uma grande quantidade de espectadores, e para ser encenado no palco" (2008, p. 66). Mesmo assim, destaca a autora, não há apenas um objetivo para esse tipo de tradução, "pois a montagem não é um acontecimento limitado num espaço e num tempo determinado", mas um "processo variável, que depende de muitos fatores - como atores, direção, composição do público ou local da apresentação" (Hörmanseder, 2008, p. 66). Defendendo uma estreita colaboração entre tradutor e outros profissionais do teatro (como diretores, dramaturgistas, atores, iluminadores etc.) e chamando a atenção para o papel ativo e imediato do público na recepção de um texto teatral encenado, Hörmanseder é a favor da adequação da tradução às novas convenções teatrais às quais se destina, da manutenção dos "efeitos teatrais" (como emoções ou a dimensão cômica de uma peça), da preservação das características de uma "linguagem natural" e de que se leve em consideração a "pronunciabilidade" (2008, p. 98-99). De um modo bastante geral e vago, a autora explica o que entende por "pronunciabilidade". Seriam as "características linguístico-acústicas do texto, que deve ser pronunciável pelo ator", já

18 No original: [...] "co-subject and/or co-author of the performance, competent both in textuality and stage-performativity, in verbal and gestic style, as well as acting conventions: an indispensable figure of cultural and theatrical mediation. 
que "a pronunciabilidade [...] possibilita que o objetivo e o efeito de um texto possam ser alcançados" (Hörmanseder, 2008, p. 99). Da mesma forma genérica, a estudiosa descreve "performabilidade" como sendo a adequação do texto teatral às exigências de um drama (2008, p. 105), o que torna uma tradução deste tipo muito mais uma atividade dramática do que linguística, como já havia apontado George Mounin (apud Hörmanseder, 2008, p. 105). Já a "respirabilidade" - outro conceito relevante na discussão de Hörmanseder - diz respeito à necessidade de levar em conta as pausas de respiração dos atores, estreitamente ligadas ao ritmo do texto e às emoções representadas pelo personagem (Hörmanseder, 2008, p. 101).

No âmbito deste artigo, não seria possivel chegar a definições claras desses conceitos estreitamente ligados à performance (aliás, entendemos que seria impossível chegar a definições exatas). Porém, consideramos bastante relevante a observação de Aaltonen (2000) acerca da longa sobrevida dos debates sobre esses conceitos em discussões teóricas sobre a tradução no contexto teatral. Mais do que fornecerem recursos claros de tradução, esses debates indicam acima de tudo uma tentativa de justificar o uso de estratégias tradutológicas que divergem daquelas que são usuais dentro do sistema literário. A "persistência" desses conceitos (performabilidade, pronunciabilidade, respirabilidade) pode, de acordo com Aaltonen,

ser interpretada como sendo descrições gerais de estratégias de tradução no contexto teatral, [descrições estas] que são vistas para distingui-las [as estratégias] da perspectiva dominante dentro do sistema literário sobre como deve ser a relação entre traduções e textos de partida. Enquanto a norma da tradução 'fiel' é apoiada, por exemplo, nas leis sobre os direitos autorais; uma abordagem divergente em relação ao texto-fonte, uma tradução 'livre', precisa ser justificada de alguma maneira, e as "exigências do palco", definidas com os termos "encenabilidade" e "pronunciabilidade", têm proporcionado essa justificativa. (Aaltonen, 2000, p. $43)^{19}$

Ou seja, a referência a esses conceitos faz parte de uma estratégia argumentativa para justificar desvios visíveis para qualquer leitor/espectador em relação ao texto de partida. O que fica claro com isso é que esse tipo de tradução tende a interferir de modo mais visível nas características linguísticas do texto original, justificada pelo argumento de ser a forma adequada a seu novo contexto. De um ponto de vista funcionalista, tais interferências não significam, porém, que a tradução seja menos "fiel" ao original do que as traduções do primeiro tipo, discutido acima, pois ela pode justamente tentar manter do modo mais "fiel" possível a qualidade dramática do texto de partida, fazendo para isso as necessárias alterações lexicais, pragmáticas ou culturais. Para poder ser considerada "adequada para o palco", a tradução precisa, portanto, cumprir exigências diversas daquelas de uma tradução "adequada" para uma recepção dentro do sistema literário.

Muitos profissionais do teatro referem-se apenas a este tipo de tradução quando falam da tradução teatral e ressaltam a importância de interferências autorais por

19 No original: The persistence of concepts such as speakability, playability and performability can be read as generalized descriptions of translation strategies in the theatre which are seen to set them apart from the dominant view in the literary system of how translations should relate to their source texts. If the norm is the 'faithful' translation, supported by, for example, copyright law in the legal system, a deviant approach to the source text, a 'free' translation, must be justified in some way, and the 'requirements of the stage' defined in terms of 'playability' and 'speakability' have provided this justification. [tradução nossa] 
parte do tradutor, do dramaturgista e/ou do diretor em relação ao texto original afastando-se nesse quesito da postura tradicional de tradutores literários. $O$ estudioso de teatro Patrice Pavis, por exemplo, usa palavras claras ao defender que "não se trata de procurar a equivalência entre dois textos, mas a apropriação de um texto-fonte pelo texto-alvo" (Pavis, 1989, p. 27). Uma apropriação não necessariamente motivada por uma determinada ideologia política, mas pelas convenções do respectivo sistema teatral. Pavis ainda complementa que "fazer um texto legível envolve fazê-lo visível - em outras palavras, disponível para uma concretização no palco e pelo público" (1989, p. 28).

Um exemplo de uma tradução performável publicada em formato de livro é "No pântano dos gatos..." (2017), título dado à versão brasileira do drama By the Bog of Cats... (1998), da dramaturga irlandesa Marina Carr. A peça foi traduzida por Alinne Balduino Pires Fernandes, que, nos paratextos, não deixa dúvida de que entendeu como relevante o potencial performático de sua tradução no âmbito da cena teatral brasileira. Em diversos artigos publicados, Fernandes expôs ainda os desafios e as soluções encontradas no processo de produzir, em língua portuguesa, uma recriação de um drama irlandês que pudesse satisfazer as exigências do sistema teatral brasileiro (Fernandes, 2012). A tradutora procurou apresentar uma versão que tivesse potencial dramatúrgico e que pudesse servir como base para diversas montagens em solo brasileiro, "deixando o campo aberto para futuros diretores" (Pavis, 1989, p. 31). O interesse de Fernandes em chegar a um resultado que possa ser encenado, ou seja, a sua busca por uma tradução performável, é visível tanto nas opções tradutológicas de termos relacionados a características da geografia irlandesa, que a tradutora substituiu por termos mais próximos da realidade brasileira, quanto nas sugestões que ela dá para o leitor/diretor/ator, tendo em vista eventuais alterações adicionais na hora de se montar a peça. Isso fica também evidente na intensa colaboração que ela procurou estabelecer com profissionais de teatro antes de publicar o texto, incluindo a realização de leituras dramáticas e de encenações (Carr, 2017).

Além de traduções de textos teatrais publicadas em forma de livro e destinadas a serem a base para diferentes encenações, há um grande número de traduções performáveis que nunca são publicadas, mas feitas apenas para uma montagem específica. Nesses casos, o que está em primeiro plano é o respectivo projeto de um grupo ou um diretor. Trata-se também de traduções comumente denominadas "adaptações", isto é, marcadas por não traduzir o texto na sua íntegra e por fazer "acréscimos, omissões e alterações na estrutura dramática geral do cenário, do enredo e dos personagens" (Aaltonen, 2000, p. 45). Concordamos com a compreensão de Aaltonen (2000) de que o termo "adaptação" é bastante vago, mas que, ao mesmo tempo, precisamos "de um termo para descrever a estratégia tradutória" com as referidas características. Nesse sentido, evitando o uso do termo "adaptação", chamamos também esse tipo de tradução (que, na maioria das vezes, existe apenas em forma de manuscrito inédito) de "performável", independentemente do tipo e da quantidade de modificação realizada em relação ao texto de partida.

Um exemplo recente no contexto brasileiro desse tipo é a produção cênica de um clássico da dramaturgia em língua alemã, "A visita da velha senhora" [Der Besuch 
der alten Dame], do suíço Friedrich Dürrenmatt, sob a direção de Luiz Villaça e com Denise Fraga no papel da protagonista Claire Zahanassian. Segundo consta na ficha técnica da peça, a "tradução" foi realizada por Christine Röhrig (mesmo já havendo uma versão brasileira publicada em 197620), e a "adaptação" por Christine Röhrig, Denise Fraga e Maristela Chelala ${ }^{21}$. Subentende-se que o texto original foi transformado para uma versão em língua portuguesa e adaptado para se adequar ao projeto do diretor. $O$ espectador ou estudioso interessado não tem acesso à forma escrita da tradução, nem à adaptação do material textual. A crítica especializada faz suas avaliações primordialmente a partir do critério da funcionalidade do texto no palco, isto é, se o projeto performático do diretor (ou de um grupo) se insere com sucesso ou não no sistema teatral do contexto de chegada. Já que o sistema teatral não segue necessariamente as mesmas convenções do sistema literário, a tradução performável "pode usar estratégias que não seriam aceitáveis atualmente no âmbito da tradução literária" (Aaltonen, 2000, p. 7).

\section{A tradução teatral em forma de legendagem}

A legendagem é uma forma relativamente nova, mas cada vez mais presente nos palcos internacionais. Os teóricos e práticos citados até agora não se referem a este tipo de tradução nos seus textos. Yvonne Griesel, tradutora teatral e organizadora do livro "Entender o teatro mundial: legendagem, tradução, interpretação e novos caminhos" [Welttheater verstehen: Übertitelung, Übersetzung, Dolmetschen und neue Wege] (2014)22, aponta que há menos de duas décadas tratava-se ainda de um "tema exótico", mas hoje esse tipo de tradução faz parte da realidade (Griesel, 2014, p. 12). Apesar de o referido livro ser resultado de um festival que ocorreu na cidade alemã de Oldenburg, ele certamente reflete a realidade teatral da Europa atual - e provavelmente não só da Europa. Há uma imensa mobilidade de profissionais de teatro de diversas línguas, apresentações de produções artísticas em diferentes países, espectadores das mais diversas línguas maternas. O Brasil está longe desse multilinguismo europeu, mas também recebe peças teatrais de grupos estrangeiros. A apresentação no SESC Pinheiros do espetáculo em língua polonesa "Árvores abatidas" (baseado numa tradução polonesa do romance Holzfällen do escritor austríaco Thomas Bernhard), sob a direção do renomado diretor Krystian Lupa e cuja duração é de aproximadamente cinco horas, dificilmente teria encontrado uma plateia cheia e entusiasta se não fosse acompanhada por legendas (acima do palco) em português ${ }^{23}$.

Diferentemente do tipo performável, a tradução de um texto teatral para legenda não é feita para ser falada, mas para ser lida durante a apresentação. Isso requer estratégias diferentes de tradução. O tradutor teatral Uli Menke aponta para uma es-

\footnotetext{
20 Friedrich Dürrenmatt. A visita da velha senhora. Tradução Mário da Silva. São Paulo: Abril S. A. Cultural e Industrial, 1976.

21 Cf., por exemplo, <http://botequimcultural.com.br/critica-a-visita-da-velha-senhora-2/>.

22 Cf. também Yvonne Griesel. Die Inszenierung als Translat: Möglichkeiten und Grenzen der Theaterübertitelung. Frank\&Timme, Berlim: 2007 (um estudo aprofundado sobre a teoria da tradução de legendas no âmbito do teatro, acompanhado de análises de oito peças francesas e suas traduções em língua alemã em legenda).

23 Cf.: <https://mitsp.org/2018/arvores-abatidas/>. A tradução das legendas, em português, foi feita por Marcelo Paiva de Souza e Luiz Henrique Budant.
} 
pecificidade da situação de recepção desse tipo de trabalho: numa apresentação em língua estrangeira, a "recepção passiva" dos acontecimentos no palco se junta à "tarefa ativa de realizar a leitura da tradução" (Menke, 2014, p. 79). Isso pode ser fatigante para o espectador, pois ele pode não dar conta de ler as legendas no pouco tempo que tem disponível, seja pela quantidade de texto muito grande seja por este ser de difícil compreensão. Esse mesmo tipo de frustração necessariamente não acontece quando o público não entende o texto integral numa apresentação em sua língua materna, já que, "obviamente, é uma ilusão acreditar que sempre entendemos tudo na nossa língua" (Menke, 2014, p. 80). Acontece que existe uma tolerância maior para a incompreensão de passagens em língua materna, enquanto "numa confrontação com uma língua estrangeira, a falta de compreensão parece depender exclusivamente dessa outra língua"; e problemas de compreensão causados pela legendagem levam rapidamente à transformação do evento cultural em uma "experiência frustrante" (Menke, 2014, p. 80).

A chave para uma "experiência teatral bem-sucedida" na legendagem seria, de acordo com Menke, a "preparação do tradutor", que "a partir da montagem ensaiada precisa decidir, frase por frase, quanto texto pode transmitir e como fazê-lo" (Menke, 2014 , p. 80). Não há regras fixas para esse trabalho, mas Menke sugere, a partir da própria prática, um "volume de texto de, no máximo, duas linhas com 36 caracteres cada uma", para uma leitura tranquila num período de seis a dez segundos (Menke, 2014 , p. 80). Além da quantidade de caracteres, seria importante também apresentar em cada unidade da legenda apenas uma ideia, para facilitar a compreensão. Em comparação com legendas de filmes, Menke lista duas grandes diferenças: textos teatrais possuem frequentemente um grau de dificuldade mais elevado e, além disso, precisam ser visualizados ao vivo em cada apresentação, "pois a duração varia de uma apresentação para outra, mesmo se tudo correr sem nenhuma pane" (2014, p. 81).

Com ajuda de alguns exemplos, Menke ilustra bem seu modo de trabalho e algumas estratégias bastante peculiares para esse tipo de tradução. De acordo com esse autor, entre o texto falado pelos atores no palco e o volume de texto mostrado nas legendas podem ocorrer grandes reduções. Dependendo do "ritmo da apresentação", mantém-se na legenda um percentual entre 50 e 100 por cento do texto falado (Menke, 2014, p. 82). Os cortes "não representam necessariamente uma perda, pois, muitas vezes, a atuação dos atores transmite exclamações, saudações, repetições diretas, listagens e variações em forma de sinônimos", tornando desnecessária a sua repetição na legenda. Existe também a possibilidade de frases compridas serem reformuladas sem perdas significativas (por exemplo: "Eu acho que isso seja possível" aparece na legenda apenas como "Vai dar") ou de se optar por termos mais curtos para economizar na quantidade de caracteres. Segundo Menke (2014), o resultado concreto desse tipo de trabalho tradutório depende em grande medida do "ritmo da apresentação", pois é isso que indica a possibilidade ou não de traduzir metáforas, expressões idiomáticas, imagens etc. Ou seja, de acordo com esse experiente profissional, as legendas devem ser produzidas durante os ensaios ou, pelo menos, depois de o tradutor já conhecer a montagem cênica. $O$ que se perde no formato textual 
em termos de fluência, de características poéticas e informações dêiticas pode, e deve ser compensado pela atuação dos atores e "pela inteligência do público que, obviamente, percebe que não está lendo o texto na sua íntegra" (Menke, 2014, p. 82). Certamente, a decisão sobre onde e quanto pode ser cortado numa legenda só pode ser tomada quando já se conhecem a proposta e as características da montagem específica.

No seu artigo, Menke ilustra as especificidades desse tipo de tradução com dois exemplos, que não serão reproduzidos aqui em sua íntegra por estarem em alemão. O primeiro cita o trecho inicial de Verbrennungen, a versão em língua alemã da peça francesa Incendies (Wadji Mouawad). Cito aqui uma pequena passagem que representa a tradução integral de uma fala de um personagem (tradução esta que, de acordo com a categorização aqui apresentada, pode ser definida de literária) e o texto apresentado ao público em forma de legenda em língua alemã, ambas do próprio Uli Menke (2014, p. 83), apenas para ilustrar a perda em termos quantitativos.

\begin{tabular}{|l|l|}
\hline $\begin{array}{l}\text { Tradução literária do texto } \\
\text { pronunciado no palco: }\end{array}$ & Legenda: \\
Sicher, sicher, sicher, sicher, & \\
ich sehe lieber dem Flug der Vögel zu. & Sicher. \\
Reden wir nicht um den & -- \\
heißen Brei herum: & $\begin{array}{l}\text { Sicher sehe ich lieber } \\
\text { die Vögel fliegen. }\end{array}$ \\
Anstelle von Vögeln sieht & -- \\
man von hier aus Autos und das & Reden wir nicht drum herum: \\
Einkaufszentrum. & Statt Vögel sieht man hier. \\
& .. \\
\hline
\end{tabular}

É interessante mencionar ainda outro exemplo citado por Menke. Trata-se de uma montagem alemã do drama Hamlet, apresentada na Inglaterra e na Austrália, sob direção de Thomas Ostermeier. Ou seja, o público de língua inglesa vai ao teatro para ver uma montagem alemã de um texto canônico escrito, originalmente, em sua própria língua. A tradução utilizada como base para a encenação correspondia a uma atualização e modernização da linguagem shakespeariana (uma tradução performável). No entanto, "mesmo lidando com uma tradução alemã" (Menke, 2014, p. 85), num estilo já modernizado, como texto de partida, mas "que tinha pouco a ver com a dicção do original de Shakespeare" (Menke, 2014, p. 85), os tradutores optaram por não usar um estilo moderno nas legendas em língua inglesa e se voltaram para o original do bardo inglês. Na opinião de Menke, "no caso de um texto canônico desse calibre seria inadequado alterar a forma textual" (Menke, 2014, p. 85), pois isso resultaria num texto que o público-alvo poderia não tolerar. Segundo a opinião de Menke, "o público aceitou bem" os cortes efetuados em decorrência das legendas, que tornaram o texto "mais sucinto" (Menke, 2014, p. 85).

Os depoimentos de Menke apresentados acima permitem uma primeira impres- 
são quanto às peculiaridades da tradução teatral em forma de legendas. Além de legendas mostradas acima ou abaixo do palco - formatos a que Menke se refere em sua discussão - há produções cênicas que integram as legendas no próprio espetáculo, englobando-as como parte da estética da obra teatral. Uma artista que defende essa abordagem é a fundadora do coletivo teatral Théâtre du Soleil, Ariane Mnouchkine. Numa entrevista concedida a Yvonne Griesel, ela é enfática ao criticar o uso de legendas acima ou embaixo do palco: "Há uma coisa que certamente não quero: que o público desvie seu olhar da minha encenação para algum lugar longe do palco" (Mnouchkine apud Griesel, 2014, p. 30). Ela atribui esse tipo de tradução à "preguiça" (Mnouchkine apud Griesel, 2014, p. 29) dos profissionais de teatro e tem encontrado diversas soluções alternativas, integrando a legendagem às propostas performáticas. Por exemplo, mostrou as legendas numa tela de seda no fundo do palco, onde a visibilidade é melhor para o público, ou em diversas superfícies de projeção no próprio palco (Mnouchkine apud Griesel, 2014, p. 26). Dependendo do projeto cênico adotado, certamente chegar-se-á a soluções tradutológicas diferentes. Mnouchkine afirma ainda que, nesse caso de tradução, não é apenas o próprio texto de chegada, mas também o tamanho e o tipo da fonte que ganham importância e precisam ser adaptados ao cenário como um todo (Mnouchkine apud Griesel, 2014, p. 31).

\section{Conclusão}

Neste artigo, discutimos a tradução de textos teatrais escritos para uma outra língua - não abordamos a tradução "intralingual" e nem a "intersemiótica", e deixamos de lado ainda outras formas do "teatro intercultural" (Aaltonen, 2000, p. 11-27) que não estejam ligadas diretamente a textos escritos e suas versões em outras línguas. Sugerimos a diferenciação entre três tipos de tradução que ocorrem no âmbito teatral, tendo plena consciência de que tal classificação não pode ser nem estável nem definitiva - assim como toda classificação, também a nossa só pode ser parcial e relativa, pois obedece a critérios circunstanciais. Ela pode, porém, chamar a atenção para a heterogeneidade da tradução no contexto teatral e contribuir para evitar posturas tradutológicas prescritivas e/ou uma perspectiva tradutológica muito centrada no texto original e suas especificidades, chegando a estratégias tradutológicas satisfatórias e traduções "funcionalmente adequadas" no seu contexto-alvo. Desse modo, é possível também evitar avaliações qualitativas a priori de traduções teatrais feitas apenas a partir de uma comparação do material linguístico do texto de partida e o de chegada. Como vimos, para se realizar - ou avaliar - uma tradução, há um grande leque de considerações a serem feitas, das quais algumas foram abordadas aqui. 


\section{Referências}

AALTONEN, Sirkku. Translating plays or baking apple pies: A functional approach to the study of drama translation. In: SNELL-HORNBY, M.; JETTMAROVÁ, Z.; KAINDL, K. Translation as Intercultural Communication. Amsterdã, Filadélfia: John Benjamins, 1995. p. 89-98.

AALTONEN, Sirkku. Time-Sharing on Stage - Drama Translation in Theatre and Society. Clevedon, Buffalo, Toronto, Sydney: Multilingual Matters Ltd., 2000.

ARROJO, Rosemary. Oficina de Tradução: A Teoria na Prática. São Paulo: Ática, 1986.

BARBOSA, Maria Aparecida. Prefacio: petulante e supérflua introdução. In: KRAUS, Karl, 2017, p. 5-8.

BASSNETT, Susan. Translation for the theatre: Textual complexities. Essays in Poetics 15, 1990, p. 71-84.

BASSNETT, Susan. Still trapped in the labyrinth: Further reflections on translation and theatre. In: BASSNETT, Susan; LEVEFERE, André. (Org.). Constructing cultures. Clevedon: Multilingual Matters, 1998. p. 90-108.

BOHUNOVSKY, Ruth. Karl Kraus - sobre a língua, a mentira e o ser humano. In: KRAUS, Karl, 2017, p. 339-351.

CARR, Marina. No Pântano dos Gatos... Trad. Alinne Balduino P. Fernandes. São Paulo: Rafael Copetti, 2017.

FERNANDES, Alinne Balduino Pires. Between words and silences: Translating for the stage and the enlargement of paradigms. Scientia Translationis, Florianópolis, 7, 2010, p. 119-133.

FERNANDES, Alinne Balduino Pires. Travelling Plays, Travelling Audiences: From Carr's Irish Midlands to Somewhere Lost and Found in Brazil. Quaderns. Revista de Traducció, 19, p. 77-85, 2012. Disponível em: <https://core.ac.uk/download/pdf/13320932. pdf>. Acesso em: 05 maio 2019.

GRIESEL, Yvonne. Welttheater verstehen - Übertitelung, Übersetzen, Dolmetschen und neue Wege. Berlin: Alexander, 2014.

HÖRMANSEDER, Fabienne. Text und Publikum - Kriterien für eine bühnenwirksame Übersetzung in Hinblick auf eine Kooperation zwischen Translatologen und Bühnenexperten. Tübingen: Stauffenberg, 2008. 
JAKOBSON, Roman. On linguistic aspects of translation. In: VENUTI, Laurence (Org.). The Translation Studies Reader. London, New York: Routledge. 2000. cap. X, p. X-X.

KRAUS, Karl. Os últimos dias da humanidade. Trad. Mariana Ribeiro de Souza. São Paulo: Balão Editorial, 2017.

LEVY, Jiří. Die literarische Übersetzung: Die Theorie einer Kunstgattung. Trad. Walter Schamschula. Frankfurt am Main: Athenäum, 1969.

MENKE, Uli. Zweimal sechsunddreißig Zeichen Shakespeare. In: GRIESEL, Yvonne. Welttheater verstehen - Übertitelung, Übersetzen, Dolmetschen und neue Wege. Berlin: Alexander, 2014. p. 78-88.

MNOUCHKINE, Ariane. "Schön muss es sein!“ Gespräch mit Ariane Mnouchkine. In: GRIESEL, Yvonne. Welttheater verstehen - Übertitelung, Übersetzen, Dolmetschen und neue Wege. Berlin: Alexander, 2014. p. 25-36.

NORD, Christiane. Funktionsgerechtigkeit und Loyalität: Theorie, Methode und Didaktik des funktionalen Übersetzens. Berlin: Frank \& Timme, 2011.

PAVIS, Patrice. Problems of translation for the stage: interculturalismo and post-modern theatre. In: SCOLNICOV, Hanna; HOLLAND, Peter (Org.). The Play out of Context: Transferring Plays form Culture to Culture. Cambridge: Cambridge University, 1989. p. 25-44.

RABETTI, Maria de Lourdes. O laboratório do dramaturg e os estudos de genética teatral: experimentos. Revista Brasileira de Estudos da Presença. 2011. Disponível em:http://www.scielo.br/pdf/rbep/v1n2/2237-2660-rbep-1-02-00443.pdf

Acesso em: 26 de jul. 2019.

SAADI, Fátima. Dramaturgias: Estudo sobre a função do dramaturgista. Questão de crítica: revista eletrônia de críticas e estudos teatrais. 2013. Disponível em: <http:// www.questaodecritica.com.br/2013/12/dramaturgias/\#more-4167>. Acesso em: 15 de jul. 2019.

SERÓN-ORDÓÑEZ, Inmaculada. Theatre translation studies: An overview of a burgeoning field (Part II: From the early 2000s to 2014). Status Quaestionis, Roma, 7, p. 28-73, 2014. Disponível em: <https://www.academia.edu/11935215/Theatre_ translation_studies_An_overview_of_a_burgeoning_field_Part_II_From_the_early_2000s_to_2014_>. Acesso em: 10 maio 2019.

SNELL-HORNBY, Mary. Sprachbare Sprache - spielbarer Text: zur Problematik der Bühnenübersetzung. In: WATTS, Richard J.; WEIDMANN, Urs (Org.). Modes of Interpretation: Essays presented to Ernst Leisi on the occasion of his 65th birthday. Tübin- 
gen: Narr, 1984.

SOUZA, Mariana Ribeiro de. O alarde de Karl Kraus. [Entrevista concedida a Paulo Vitor Schlichting Peçanhuk]. Revista Qorpus. Universidade Federal de Santa Catarina, Pós-Graduação em Estudos da Tradução, N. 025, 2018. Disponível em: <http:// qorpus.paginas.ufsc.br/\%E2\%80\%9C-a-procura-de-autor\%E2\%80\%9D/edicao-n-025/5475-2/>. Acesso em: 22 abr. 2019.

STEINER, George. Depois de Babel - questões de linguagem e de tradução. Trad. Carlos Alberto Faraco. Curitiba: UFPR, 2005.

VENUTI, Lawrence. The translator's invisibility - A history of translation. 3 ed. New York: Routledge, 2018.

Recebido em:15/06/2019

Aprovado em: 09/07/2019 